\title{
DNA Immunization of Neonates Induces Immunity Despite the Presence of Maternal Antibody
}

\author{
Elanchezhiyan Manickan, Zhiya Yu, and Barry T. Rouse \\ Department of Microbiology, The University of Tennessee, Knoxville, Tennessee 37996-0845
}

\begin{abstract}
Neonatal animals were not considered as suitable vaccine recipients either because of immune immaturity or because passively delivered antibody interferes with immune induction. In this report, we evaluated the response of neonatal mice to immunization with naked DNA encoding a herpes simplex virus (HSV) protein, and determined if maternally derived HSV antibody interfered with immunogenicity. Our results show that neonatal mice develop effective humoral and $T$ cell responses after immunization with either DNA or inactivated vaccines. The nature of the responses to HSV immunization, however, was more Th2-like in neonates than in adults. Whereas neonatal mice from HSV-naive mothers responded well to both DNA and inactivated vaccines, only DNA immunization induced effective immunity in neonates born to immune mothers. Our results indicate that DNA vaccines might provide a useful means of immunizing young animals that still possess high levels of potentially interfering maternal antibody. (J. Clin. Invest. 1997. 100:2371-2375.) Key words: DNA • HSV • neonate • maternal antibody $\bullet$ vaccine
\end{abstract}

\section{Introduction}

Newborns and the very young are rarely if ever given vaccines, yet vaccinating this age group against some agents could provide a valuable means of breaking cycles of agent transmission. Herpes simplex virus (HSV) ${ }^{1}$ infection may represent such an example. Infection likely occurs at a very young age, and once this has occurred the stage is usually set for lifelong persistence of virus with periodic episodes of clinical or subclinical reexpression (1). Conceivably, immune induction during infancy might preclude infection or could be devised to establish a pattern of immune reactivity that limits clinical expression after reactivation from latency. Neonates are not usually considered as suitable vaccine recipients either because of immune immaturity, or because maternally derived passive antibody interferes with active immune induction (2-5). The latter effect

Address correspondence to Barry T. Rouse, Department of Microbiology, The University of Tennessee, Knoxville, TN 37996-0845. Phone: 423-974-4026; FAX: 423-974-4007.

Received for publication 21 May 1997 and accepted in revised form 27 August 1997.

1. Abbreviations used in this paper: APC, antigen-presenting cells; $\mathrm{HSV}$, herpes simplex virus.

J. Clin. Invest.

(C) The American Society for Clinical Investigation, Inc. 0021-9738/97/11/2371/05 \$2.00

Volume 100, Number 9, November 1997, 2371-2375

http://www.jci.org provides an obstacle to early immunization against several human and veterinary pathogens (3-6).

Recently, naked plasmid DNA was shown to represent an effective means of immunizing against several agents, including HSV (7-11). Naked DNA administration, given to muscles, leads to uptake and long-term expression by antigen-presenting cells (APC) such as dendritic cells (12-14). This form of immunization might be refractory to uptake interference by antibody, and targeting APC may provide a durable source of antigen that should maximize eventual immune induction. Nevertheless, in some systems, immunization of 2-5-d-old mice with DNA vaccines was observed to induce neonatal tolerance rather than immunity (15). In this report, we evaluated the response of neonatal mice to immunization with naked DNA encoding an HSV protein, and determined if maternally derived HSV antibody interfered with immunogenicity. Our results show that neonatal mice develop effective humoral and $\mathrm{T}$ cell responses after immunization with either DNA or inactivated vaccines. The nature of the responses to HSV immunization, however, was more $\mathrm{Th} 2^{1}$-like in neonates than in adults. Whereas neonatal mice from HSV-naive mothers responded well to both DNA and inactivated vaccines, only DNA immunization induced effective immunity in neonates born to immune mothers. Our results indicate that DNA vaccines might provide a useful means of immunizing young animals that still possess high levels of potentially interfering maternal antibody.

\section{Methods}

Plasmid DNA preparation. This procedure has been described in detail elsewhere (16). In brief, a full-length $\mathrm{gB}^{1}$ gene was expressed in the plasmid pc-DNA-I under the control of a cytomegalovirus promoter. Plasmid DNA, after growth in Escherichia coli, was purified using plasmid DNA isolation columns (Promega Corp., Madison, $\mathrm{WI}$, and the purity and concentrations were determined. pc-DNA without $\mathrm{gB}$ acted as the vector control material.

Virus and cells. HSV-1 stains KOS and I7 were grown on vero cell monolayers (no. CCL81; American Type Culture Collection, Rockville, MD) and stored at $-80^{\circ} \mathrm{C}$ until use.

Mice. 3-4-wk-old BALB/c mice were obtained from Harlan Sprague-Dawley (Indianapolis, IN). Breeding was begun at 5-6 wk. Breeding was done at the Laboratory Animal Facility (College of Veterinary Medicine, Knoxville, TN). Animal facilities and the investigators are accredited by the American Association for Accreditation of Laboratory Animal Care.

Neonatal and adult mouse immunization. To obtain infant mice, groups of female BALB/c mice (5-6-wk-old) were immunized intramuscularly $(50-\mu \mathrm{l} \mathrm{vol})$ with $10^{7} \mathrm{pfu}^{1} /$ mice of HSV-1 (KOS strain, HSV-immune group) or PBS (pH 7.2, naive group). $1 \mathrm{~d}$ after immunization, breeding was begun, and pregnant animals were identified. 2 wk after conception, mothers were boosted with $50 \mu \mathrm{l}$ of UV-inactivated HSV-1 (strain KOS, $10^{7}$ pfu/mice before inactivation). $24 \mathrm{~h}$ after parturition, mother mice were bled by retroorbital puncture, and the serum was analyzed for gB-specific antibodies. Pups were used for immunization at $\sim 24 \mathrm{~h}$ after birth, at which time all animals had suckled colostrum. Suckling mice from nonimmunized as well as im- 
munized mothers were vaccinated in the thigh region with various antigens described in Results. In brief, injections were delivered in a 10$\mu \mathrm{l}$ vol and animals received gB-DNA $(100 \mu \mathrm{g})$, vector-DNA $(100 \mu \mathrm{g})$, or UV-inactivated HSV-1-KOS ( $10^{7}$ pfu before UV-inactivated) or PBS ( $\mathrm{pH}$ 7.2). At the age of $3 \mathrm{wk}$, mice were weaned, and the sexes were separated. Age-matched neonatal vaccinated female mice were used for the experiments described below. Mice were test-bled at 4 and 6 wk when some experiments were terminated.

Antibody assays. At 4 and $6 \mathrm{wk}$ after immunization, five animals from each group were bled. Equal volumes of serum were obtained, and pools were screened for $\mathrm{gB}$-specific $\mathrm{G}$ IgG using a standard quantitative ELISA described previously (17). The same sera were analyzed for neutralizing antibodies by a serum-neutralization (SN) assay (16). The gB antigen was generously supplied by Dr. Rae Lyn Burke of Chiron Corp. (Emeryville, CA)

T cell assays. $6 \mathrm{wk}$ after immunization, splenocytes obtained from five mice of various groups were pooled and analyzed for HSV-specific lymphoproliferation as described in detail elsewhere (17). In brief, immune splenocytes (responders) were collected and restimulated in vitro $\left(4 \mathrm{~d}\right.$ at $\left.37^{\circ} \mathrm{C}\right)$ with varying ratios of stimulator cells that were $\mathrm{x}$-irradiated naive syngeneic spleen cells infected at a multiplicity of infection (moi) of 1.5 with UV-HSV-1 (KOS strain). $18 \mathrm{~h}$ before the harvest, $1 \mu \mathrm{Ci} /$ well of $\left[{ }^{3} \mathrm{H}\right] \mathrm{TdR}$ was added to all wells, and harvesting cells were measured for radioactivity by $\beta$ scintillation. Results were expressed as total cpm $\left[{ }^{3} \mathrm{H}\right] \mathrm{TdR}$ incorporation as well as by standard stimulation index.

A portion $\left(10^{6}\right.$ cells $)$ of the cells used for the lymphoproliferation assays were screened for their cytokine profile by a procedure described previously (17). For these assays, $10^{6}$ cells were suspended in $1 \mathrm{ml}$ of RPMI-10\% FCS in a 12-well tissue culture plate. Cells from each vaccinated group were divided into three sets. One set of $10^{6}$ cells were in vitro-restimulated with UV-HSV-1 (KOS; 1.5 moi) and the other groups with $5 \mu \mathrm{g}$ of concanavalin A (con-A) or none. All these cells were incubated at $37^{\circ} \mathrm{C}$ for $72 \mathrm{~h}$, and the supernatant from each well was collected, aliquoted, and stored at $-20^{\circ} \mathrm{C}$ until used. These supernatants were analyzed for various cytokines as per the previously described procedure (17). IFN- $\gamma$ was detected by using ELISA (IFN- $\gamma$ ELISA minikit; Endogen, Cambridge, MA). IL-2 and IL-4 were detected by bioassays using CTLL-2 and CT4.S cells (cells and IL-4 were kind gifts of Dr. Cynthia Watson, National Institutes of Health, Bethesda, MD), respectively. Concentrations of the cytokines were derived from the standard curves.

Delayed-type hypersensitivity (DTH) assays. Four mice from each group were tested for the DTH response using the protocol described elsewhere (18). In brief, on the day of testing, each mouse was injected with $20 \mu \mathrm{l}$ of UV-inactivated HSV-1.17 $\left(10^{7}\right.$ pfu before inactivation) in the right ear pina, and the same volume of vero cell extract in the left. Ear thickness was measured at -1 and 48 of injection, and the values were expressed as $n \cdot 10^{-2} \mathrm{~mm}$. Mean increase in ear thickness was calculated by subtracting values at $-1 \mathrm{~h}$ from $48 \mathrm{~h}$. Values obtained from the vero cell extract-injected ears were further subtracted from the HSV injected ears and the data presented.

Virus infection. Immunized mice were challenged with HSV-1.17 as described elsewhere (17). In brief, 6 wk after immunization just before challenge, the left flanks of anaesthetized mice were depilated and scarified, and $20 \mu \mathrm{l}$ containing $10^{4}$ pfu $\left(10 \mathrm{ID}_{50}\right)$ or $5 \times 10^{5} \mathrm{pfu}$ (500 ID $\mathrm{ID}_{50}$ ) of HSV-1 (17 strain) was added and the flanks were gently massaged. Animals were observed daily for ipsilateral zosteriform lesions as described in detail elsewhere (17). Severity of the lesions were scored in a blinded fashion as follows: $1+$, vesicle formation; $2+$, local erosion and ulceration of the local lesion; $3+$, mild to moderate ulceration; 4+, severe ulceration, hind limb paralysis, and encephalitis. Animals that failed to develop zoster lesions have no detectable viruses (by virus isolation and titration) at the injection site after 2-3 d of cutaneous infection, and do not develop lesions at a later period. Animals that progressed to $1+$ clinical lesion never recovered, and they usually proceeded to $4+$ lesions before death. Animals with $4+$ lesions were killed.

\section{Results}

In previous experiments with young adult mice, plasmid DNA encoding $\mathrm{gB}$ was shown to induce several aspects of adaptive immunity, and provided protection against systemic (17) and mucosal challenge with HSV (19). This construct was used to immunize two groups of neonatal mice, one group born to mothers previously unexposed to HSV, and the other group whose mothers were immunized with HSV, and who had high titers of $\mathrm{gB}$-specific antibody (Table I). Neonatal mice from both groups were also immunized with UV-inactivated HSV, or with vector DNA. Animals were test-bled at 4 and $6 \mathrm{wk}$ when animals were killed for the measurement of cell-mediated immunity. Additional groups of similarly immunized animals were used to assess T cell immunity by DTH, as well as their level of resistance upon systemic challenge with HSV. The results are expressed in Tables I-III. It is to be pointed out

Table I. GB-specific Serum Antibody Response at Different Time Points to HSV Antigens in Neonatal Mice (ng/ml)

\begin{tabular}{|c|c|c|c|c|c|c|c|c|c|c|c|}
\hline \multirow{2}{*}{$\begin{array}{l}\text { Immune status } \\
\text { of mother }\end{array}$} & \multirow[b]{2}{*}{ Vaccine given to newborns ${ }^{\ddagger}$} & \multicolumn{5}{|c|}{$4 \mathrm{wk}$ p. ..$^{\mathrm{II}}$} & \multicolumn{5}{|c|}{$6 \mathrm{wk}$ p.i. } \\
\hline & & Total IgG & $\operatorname{IgG} 2 \mathrm{a}$ & IgG1 & IgG2a/IgG1 ratio & SN & Total IgG & $\operatorname{IgG} 2 \mathrm{a}$ & IgG1 & $\mathrm{IgG} 2 \mathrm{a} / \mathrm{IgG} 1$ ratio & SN \\
\hline Naive $^{\S}$ & gB-DNA & $4825^{*}$ & 2140 & 3018 & 0.7 & 8 & 5313 & 1560 & 3710 & 0.4 & 16 \\
\hline Naive & vector-DNA & $<10$ & $<10$ & $<10$ & - & $<2$ & $<10$ & $<10$ & $<10$ & - & $<2$ \\
\hline Naive & UV-HSV & 31243 & 12562 & 21426 & 0.6 & 32 & 28608 & 9105 & 13640 & 0.7 & 32 \\
\hline Naive & PBS & $<10$ & $<10$ & $<10$ & - & $<2$ & $<10$ & $<10$ & $<10$ & - & $<2$ \\
\hline $\mathrm{HSV}^{\|}$ & gB-DNA & 7512 & 2371 & 6728 & 0.3 & 16 & 10944 & 3412 & 7089 & 0.5 & 16 \\
\hline HSV & vector-DNA & 765 & 257 & 322 & 0.8 & 2 & $<10$ & $<10$ & $<10$ & - & $<2$ \\
\hline HSV & UV-HSV & 412 & 185 & 478 & 0.4 & 2 & $<10$ & $<10$ & $<10$ & - & $<2$ \\
\hline HSV & PBS & 597 & 288 & 346 & 0.7 & 2 & $<10$ & $<10$ & $<10$ & - & $<2$ \\
\hline
\end{tabular}

*gB-specific antibody was measured by ELISA as described in Methods. ${ }^{*}$ Adult mice immunized with gB-DNA or UV-HSV expressed higher gBspecific IgG response (12,859 and 22,455 $\mathrm{ng} / \mathrm{ml}$ respectively), but the IgG isotype showed predominance of IgG2a (in the gB-DNA group the IgG2a/ IgG1 ratio was 11.7 and in the UV-HSV group it was 2.4). SN, serum neutralization titer. ${ }^{\circledR}$ Mice unexposed to HSV. "HSV naive and immune mothers were bled at day 1 after parturition. HSV immune mothers (four mice) showed a mean antibody titer (gB specific by ELISA) of 27,283 $\pm 6,450 \mathrm{ng} / \mathrm{ml}$

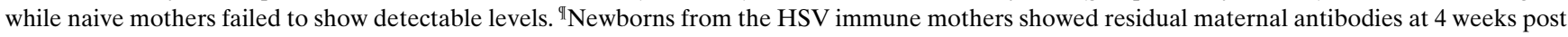
immunization (see vector DNA group and PBS group). p.i., postinfection; SN, serum-neutralizing antibodies. 


\begin{tabular}{|c|c|c|c|c|c|c|c|}
\hline \multirow{2}{*}{$\begin{array}{l}\text { Immune status } \\
\text { of mother }\end{array}$} & \multirow{2}{*}{$\begin{array}{l}\text { Vaccine given } \\
\text { to newborns }\end{array}$} & \multirow{2}{*}{$\begin{array}{c}\text { Lymphoproliferation* CPM } \\
\text { of responders + HSV stimulators }\end{array}$} & \multirow{2}{*}{$\begin{array}{c}\text { Stimulation } \\
\text { index } x^{\ddagger 8}\end{array}$} & \multicolumn{4}{|c|}{ Cytokine production $^{\| \pi}$} \\
\hline & & & & IFN- $\gamma$ & IL-2 & IL-4 & $\mathrm{DTH}^{* *, \ldots \neq}\left(10^{-2} \mathrm{~mm}\right)$ \\
\hline & & & & $\mathrm{pg} / \mathrm{ml}$ & $\mathrm{pg} / \mathrm{ml}$ & $\mathrm{pg} / \mathrm{ml}$ & $\mathrm{pg} / \mathrm{ml}$ \\
\hline Naive & gB-DNA & $15938 \pm 658$ & 16.7 & 761 & 3658 & 321 & $5.9 \pm 0.8$ \\
\hline Naive & vector-DNA & $859 \pm 322$ & 1.2 & $<50$ & $<10$ & $<10$ & $0.2 \pm 0.1$ \\
\hline Naive & UV-HSV & $20145 \pm 769$ & 25.9 & 1838 & 5418 & 546 & $11.9 \pm 1.6$ \\
\hline Naive & PBS & $356 \pm 279$ & 0.7 & $<50$ & $<10$ & $<10$ & $0.4 \pm 0.2$ \\
\hline HSV & gB-DNA & $11483 \pm 965$ & 13.2 & 1459 & 4633 & 198 & $5.5 \pm 0.3$ \\
\hline HSV & vector-DNA & $958 \pm 405$ & 0.9 & $<50$ & $<10$ & $<10$ & $0.5 \pm 0.2$ \\
\hline HSV & UV-HSV & $1828 \pm 629$ & 1.8 & 93 & $<10$ & $<10$ & $0.2 \pm 0.1$ \\
\hline HSV & PBS & $689 \pm 325$ & 1.2 & $<50$ & $<10$ & $<10$ & $0.6 \pm 0.4$ \\
\hline
\end{tabular}

*6 wk after neonatal immunization, spleen cells (responder cells) were restimulated in vitro with HSV-infected x-irradiated syngeneic spleen cells (stimulator cells) for $5 \mathrm{~d}$ at $37^{\circ} \mathrm{C}$. cpm of incorporated $\left[{ }^{3} \mathrm{H}\right]$ thymidine was measured after an 18 -h pulse. ${ }^{*}$ The ratio of cpm of responders $+\mathrm{HSV}$ stimulators versus cpm of responders + naive stimulators. ${ }^{\S}$ Adult mice that received gB-DNA or UV-HSV showed stimulation indices of 20.4 and 30.8 , respectively. "Culture supernatants obtained from 72-h UV-HSV pulsed splenocytes were screened for cytokines as described in Methods. ${ }^{\mathbb{I}}$ Not shown in the table are the data from supernatants of Con-A-stimulated splenocytes (positive control) that showed the presence of all cytokines tested. Splenocytes obtained from adult mice immunized with gB-DNA upon in vitro restimulation with UV-HSV produced 4295 , 3948, and $>10$ pg/ml of IFN- $\gamma$, IL-2, and IL-4, respectively. **DTH responses to HSV-1.17 (UV-inactivated) were measured as described in Methods. Values obtained from vero cell extract-injected ears were subtracted from the values recorded from HSV-injected ears. Table represents the mean increase in thickness at $48 \mathrm{~h}$. Four mice were used from each group for this analysis. ${ }^{\ddagger}$ DTH testing done on adult mice showed that gB-DNA and UV-HSV vaccine recipients had a mean increase of $7.6 \pm 1.9$ and $12.1 \pm 2.0$, respectively, to UV-HSV-1.17 ear challenge. Table represents one of the three experiments, all of which showed comparable results.

that at $4 \mathrm{wk}$, pups born to HSV-immune mothers still had antiHSV antibody. By 6 wk such passively acquired antibodies had disappeared.

Responses to neonatal immunization were evident by $4 \mathrm{wk}$, although at this time residual maternal antibody was still present that ranged in concentration of $185-765 \mathrm{pg} / \mathrm{ml}$ (Table I). By 6 wk such neonatally acquired antibody had disappeared. It is apparent that mice do develop antibody responses to HSV after neonatal immunization. It is evident from the pattern of $\mathrm{IgG}$ isotype responses measured at $6 \mathrm{wk}$ that re- sponses were more Th2-like than was the case in mice immunized as young adults (Table I). Accordingly, the ratio of $\mathrm{IgG}_{2 \mathrm{a}}: \mathrm{IgG}_{1}$ was much lower in neonates than in mice immunized as young adults. Upon $\mathrm{gB}$ DNA vaccination of neonates from either nonimmune or immune mothers, antibody responses measured $6 \mathrm{wk}$ later were of similar magnitude (5313 and $10944 \mathrm{pg} / \mathrm{ml}$, respectively) and IgG isotype pattern (Table I). Whereas neonates from HSV-naive mothers developed responses to inactivated virus that were fivefold superior to those immunized with gB DNA, however, neonates from

Table III. Neonatal Immunization of BALB/C Mice with GB-DNA-induced Protection Against HSV Infection

\begin{tabular}{|c|c|c|c|c|c|}
\hline \multirow{3}{*}{$\begin{array}{l}\text { Immune status } \\
\text { of mother* }\end{array}$} & \multirow[b]{3}{*}{ Vaccine given to neonates ${ }^{\ddagger}$} & \multicolumn{4}{|c|}{ Percent protection after $10 \mathrm{ID}_{50}$ virus challenge $\mathrm{e}^{\S, \|}$} \\
\hline & & \multicolumn{2}{|c|}{ Experiment 1} & \multicolumn{2}{|c|}{ Experiment 2} \\
\hline & & day 10 & day 14 & day 10 & day 14 \\
\hline Naive & gB-DNA & $80(4.0)$ & $80(\mathrm{D})^{\mathrm{q}}$ & $70(3.7)$ & 70 (D) \\
\hline Naive & vector-DNA & $<1(3.5)$ & $<1(\mathrm{D})$ & $<1(4.0)$ & $<1(\mathrm{D})$ \\
\hline Naive & UV-HSV & 100 & 100 & 100 & 100 \\
\hline Naive & PBS & $<1(3.9)$ & $<1(\mathrm{D})$ & $<1(3.6)$ & $<1(\mathrm{D})$ \\
\hline HSV & gB-DNA & $70(3.0)$ & 70 (D) & $80(4.0)$ & $80(\mathrm{D})$ \\
\hline HSV & vector-DNA & $<1(4.0)$ & $<1(\mathrm{D})$ & $<1(4.0)$ & $80(\mathrm{D})$ \\
\hline HSV & UV-HSV & $10(4.0)$ & 10 (D) & $30(3.5)$ & $20(\mathrm{D})$ \\
\hline HSV & PBS & $<1(3.8)$ & $<1$ (D) & $10(4.0)$ & $<1(\mathrm{D})$ \\
\hline
\end{tabular}

*BALB/c mice were immunized in the foot pad with UV-HSV-1-KOS (107 pfu) (HSV group) or equal volume of PBS (naive group). Pregnant female mice were boosted with the respective antigens at $\sim 2 \mathrm{wk}$ after conception. $* 24$-h-old pups were immunized with various vaccines in $10 \mu l$ vol. s.c. into the thigh region. ${ }^{8} 6 \mathrm{wk}$ after immunization, mice were challenged with $10^{4}$ pfu (low dose) of HSV $\left(10 \mathrm{ID}_{50}\right)$ on the scarified skin of the flank. Not shown in the table are the data of mice that received $500 \mathrm{ID}_{50}$ of HSV-1.17 (high dose), all of which died by day 14 except naive mother-derived pups immunized with UV-HSV. "Values in the parenthesis represent the mean clinical score of the lesion-developed animals. D, lesion-developed animals died. "Adult BALB/c (3-4 wk) receiving gB-DNA or UV-HSV showed protection of 90 or $100 \%$, respectively, at low dose virus challenge. The protection, however was only 20 and $100 \%$ virus, respectively, at high viral dose. 
HSV-immune mothers failed to generate detectable HSV-specific antibody. Serum virus neutralization tests indicated that both immune and naive pups had titers of 16 upon gB-DNA immunization. In contrast, vaccination of those groups with UV-HSV indicated that only naive group developed a neutralizing antibody (titer 32) while immune pups failed to show any serum neutralization.

A similar pattern of reactivity was revealed by in vitro measures of $\mathrm{T}$ cell immunity. Thus, as shown in Table II, after $\mathrm{gB}$ DNA immunization, both groups of neonates developed similar levels of $\mathrm{T}$ cell immunity detected by lymphoproliferation and antigen-induced cytokine production. Splenocytes obtained from naive and immune pups vaccinated with gB-DNA showed HSV-specific lymphoproliferation, and the stimulation indices were 16.7 and 13.2, respectively. Such proliferative responses, however, only occurred in UV-HSV immune pups from naive mothers. Splenocytes from newborns of immune mothers failed to proliferate to HSV antigen despite prior immunization with UV-HSV.

Interestingly, the cytokine pattern showed that both Th1 and Th2 T cells were induced in neonates, but as observed previously (17), similarly immunized adults showed almost exclusively a Th1 pattern of responsiveness to DNA immunization. As with humoral immunity, it was evident that neonatal mice born to nonimmunized mothers generated $\mathrm{T}$ cell immunity upon immunization with inactivated vaccine. In contrast, neonates with maternal antibody failed to respond. The pattern of responsiveness evident from in vitro assays was also apparent by in vivo measurement of DTH. Thus, mice of both neonatal groups developed DTH responses after DNA immunization, but only the neonatal mice from naive mothers responded to inactivated vaccine (Table II).

Finally, as shown in Table III, the pattern of immune events shown by neonatally immunized mice by antigen-specific in vitro assays was confirmed by the results of virus challenge experiments. Mice from both neonatal groups (immune and nonimmune mothers) developed resistance to HSV challenge after DNA immunization. In addition, neonates from nonimmune mothers resisted challenge, and in fact had absolute immunity after immunization with inactivated vaccine. Neonates from immune mothers vaccinated with inactivated virus, however, succumbed to challenge.

In a separate experiment, adult BALB/c mice were injected intravenously with $200 \mu \mathrm{g}$ of anti-HSV serum or naive mouse serum in a $200-\mu l$ volume. $6 \mathrm{hrs}$ later, those mice were immunized intramuscularly with either gB-DNA or vector DNA or UV-HSV-1 (KOS). 3 wk later, those mice were challenged with $10^{4}$ pfu of HSV-1.17. Interestingly, only the gBDNA recipients were protected from zoster lesions. UV-HSV and vector DNA immune mice succumbed to show clinical lesions (data not shown). Taken together, it is apparent that neutralizing antibodies, either naturally or artificially acquired, fail to inhibit successful immune responses to DNA vaccination.

\section{Discussion}

This report demonstrates that immunization of newborn mice with plasmid DNA encoding the major glycoprotein $\mathrm{gB}$ is an effective means of inducing HSV-specific immunity. The approach was equally effective in neonates born to nonimmune mothers, as well as those whose mothers were HSV-immune, and who received passive antibody reactive with the $\mathrm{gB}$ protein. In contrast, whereas naive neonates responded with even higher levels of immunity after vaccination with inactivated virus than occurred after DNA immunization, detectable immune responses did not occur in passively immune neonates given inactivated vaccine. These results emphasize that DNA vaccines do provide a valuable means of inducing immunity in young animals, even at a time when they have high levels of passive immunity that may interfere with other forms of vaccination. The reason such passive antibody fails to interfere with DNA vaccines remains to be shown, but it presumably relates to the likelihood that antibody does not impede DNA access to APC, and that such cells may express antigen for prolonged periods in vivo (8).

Even though there is frequently a need to vaccinate animals soon after birth, this is not done either because animals are expected to be immature immunologically, or because the passively received antibodies interferes in some way with immune induction (5). The latter is a particular problem for vaccines designed to protect against parainfluenza viruses $(3,4)$. Currently, no licensed vaccine exists for HSV, and infection by this virus is likely to occur in many individuals during infancy (20). Conceivably, prophylactic vaccines might prevent infection and the establishment of latency, which together set the stage in many individuals for a lifetime of recurrent episodes of clinical disease. DNA vaccines against HSV are under clinical trial, although not for use in children.

Only two published reports have described the use of DNA vaccines in infant mice, and in one of these reports the outcome was immunological tolerance rather than immunity (15, 21). Indeed, induction of tolerance was only achieved with the DNA vaccine, and was not observed with other vaccine formulations (15). It was supposed that tolerance induction occurred because the immunogenic proteins or peptides newly synthesized after DNA administration might be in a tolerogenic form. If true for the CSP protein of malaria, it was not the case with the HSV DNA vaccine studied in this report, nor was the effect observed in newborns immunized against influenza (21). In fact, it appears that inducing complete immunological tolerance against viral antigens in newborn mice with any antigen formulation is difficult to achieve. More common, however, is the production of an immune response whose pattern differs from that of the adult (22-26). Thus, classical studies on neonatal tolerance to LCMV reviewed that the tolerance affected CTL but not antibody response (27). It is commonly observed that nature of the $\mathrm{T}$ cell response after neonatal antigen exposure emphasizes Th2 rather than Th1 (22-26); this was also the case in our studies with DNA vaccination. Why such a pattern of responsiveness should occur has yet to be resolved. Suggestions have included qualitative differences in the function of newborn T cells upon antigen stimulation, an inefficiency of neonatal APC, and quantitative differences in the number of responder T cells (2). Interestingly, the pattern of immune responsiveness established at birth in some systems is retained in the form of memory $(24,26)$. This situation may be beneficial where the Th2 pattern is crucial for immunity, but is problematic if resistance is predominantly a property of Th1-mediated immunity. As some studies have indicated, Th2 domination after neonatal immunization is not an inevitable consequence (24), and DNA vaccines represent an immune strategy that can be manipulated with ease to engender a required type of immune response (28). Reports that this result can be achieved 
in adults have been made (11), and we are seeking to determine if DNA vaccines in neonates can be engineered to emphasize Th1 mediated immunity. We are currently attempting to achieve this goal.

Our study is, as far as we know, the first to evaluate the immunogenicity of DNA vaccines in neonates that are passively immune at the time of vaccination. This observation bodes well for the use of DNA vaccines in the critical time during infancy when animals respond poorly to vaccines because of existing immunity. The approach merits investigation against measles, respiratory syncytial virus, and parainfluenza where maternal antibody acts as a major obstacle by early vaccination $(3,4,29)$.

\section{Acknowledgments}

We thank Paula Keaton for word processing.

This work was supported by National Institutes of Health grant AI 14981.

\section{References}

1. Whitley, R.J. 1996. Herpes simplex virus. In Fields Virology. B.N. Fields, D.M. Knipe, and P.M. Howley, editors. Lippincott-Raven Publishers, Philadelphia. 2297-2342.

2. Bona, C., and A. Bot. 1997. Neonatal immuno-responsiveness. The Immunologist. 5:5-9.

3. Albrecht, P., F.A. Ennis, and E.J. Saltzman. 1977. Persistence of maternal antibody in infants beyond 12 months: mechanisms of measles vaccine failure. J. Pediatr. 91:715-718.

4. Murphy, B.R., R.A. Olmsted, P.L. Collins, R.M. Chanock, and G.A. Prince. 1988. Passive transfer of respiratory syncytial virus (RSV) antiserum suppresses the immune response to the RSV fusion (F) and large (G) glycoproteins expressed by recombinant vaccinia viruses. J. Virol. 62:3907-3910.

5. Van Maanen, C., G. Bruin, and E. deBoer-Liujtze. 1992. Interference of maternal antibodies with the immune response of foals after vaccination against equine influenza. Vet. Q. 14:13-17.

6. Winters, W.D. 1981. Time dependent decreases of maternal canine virus antibodies in newborn pups. Vet. Rec. 108:295-299.

7. Ulmer, J.B., J.C. Sadoff, and M.A. Liu. 1996. DNA vaccines. Curr. Opin. Immunol. 8:531-536.

8. Ertl, H.C.J., and Z. Xiang. 1996. Novel vaccine approaches. J. Immunol. 156:3579-3582.

9. Whalen, R.G. 1996. DNA vaccines for emerging infectious diseases: what if? Emerg. Infect. Dis. 3:168-175.

10. Kumar, V., and E. Sercarz. 1996. Genetic vaccination: the advantages of going naked. Nat. Med. 8:857-859.

11. Manickan, E., K.L. Karem, and B.T. Rouse. 1997. DNA vaccines-a modern gimmick or a boon to vaccinology? Crit. Rev. Immunol. 17:139-154.
12. Doe, B., M. Selby, S. Barnett, J. Baenziger, and C.M. Walker. 1996. Induction of cytotoxic T-lymphocytes by intramuscular immunization with plasmid DNA is facilitated by bone marrow-derived cells. Proc. Natl. Acad. Sci. USA. 93:8578-8583.

13. Condon, C., S.C. Watkins, C.M. Celluzzi, K. Thompson, and L.D. Falo, Jr. 1996. DNA based immunization by in vivo transfection of dendritic cells. Nat. Med. 10:1122-1128.

14. Ulmer, J.B., R.R. Deck, C.M. DeWitt, J.J. Donnelly, and M.A. Liu. 1996. Generation of MHC class I-restricted cytotoxic T-lymphocytes by expression of a viral protein in muscle cells: antigen presentation by nonmuscle cells. Immunology. 89:59-67.

15. Mor, G., G. Yamshchikov, M. Sedegah, M. Takeno, R. Wang, R.A Houghton, S. Hoffman, and D.M. Klinman. 1996. Induction of neonatal tolerance by plasmid DNA vaccination of mice. J. Clin. Invest. 12:2700-2705.

16. Rouse, R.J.D., S.K. Nair, S.L. Lydy, J.C. Bowen, and B.T. Rouse. 1994. Induction of primary cytotoxic T-lymphocyte responses with DNA encoding herpes simplex virus proteins. J. Virol. 68:5686-5689.

17. Manickan, E., R.J.D. Rouse, Z. Yu, W.S. Wire, and B.T. Rouse. 1995. Genetic immunization against herpes simplex virus. Protection is mediated by CD4+ T lymphocytes. J. Immunol. 155:259-265.

18. Manickan, E., S. Kanangat, R.J.D. Rouse, Z. Yu, and B.T. Rouse. 1997. Enhancement of immune response to naked DNA vaccine by immunization with transfected dendritic cells. J. Leukocyte Biol. 61:125-132.

19. Kuklin, N., M. Daheshia, K. Karem, E. Manickan, and B.T. Rouse. 1997. Induction of mucosal immunity against herpes simplex virus by plasmid DNA immunization. J. Virol. 4:3138-3145.

20. Mester, J.C., G.N. Milligan, and D.I. Bernstein. 1996. Immunology of herpes simplex virus. In Genital and Neonatal Herpes. L.R. Stanberry, editor. John Wiley \& Sons, Ltd., Bristol, UK. 49-91.

21. Bot, A., S. Bot, A. Garcia-Sastre and C.A. Bona. 1996. DNA immunization of newborn mice with a plasmid-expressing nucleoprotein of influenza virus. Viral Immunol. 9:207-210.

22. Ridge, J.P., E.J. Fuchs, and P. Matziner. 1996. Neonatal tolerance revisited: turning on newborn T cells with dendritic cells. Science (Wash. DC). 271 1723-1726.

23. Sarzotti, M., D.S. Ribbons, and P.M. Hoffman. 1996. Induction of protective CTL responses in newborn mice by a murine retrovirus. Science (Wash. DC). 271:1726-1728.

24. Forstherber, T., H.C. Yip, and P.V. Lehman. 1996. Induction of Th1 and Th2 immunity in neonatal mice. Science (Wash. DC). 271:1728-1730.

25. Barrios, C., P. Brawand, M. Berney, C. Brandt, P. Lambert, and C. Siegrist. 1996. Neonatal and early life immune responses to various forms of vaccine antigens qualitatively differ from adult responses: predominance of a Th-2 biased pattern which persists after adult boosting. Eur. J. Immunol. 26:14891496.

26. Garza, K., N.D. Griggs, and K.S.K. Tung. 1997. Neonatal injection of an ovarian peptide induces autoimmune ovarian disease in female mice: requirement of endogenous neonatal ovaries. Immunity. 6:89-96.

27. Buchmeier, M.J., R.M. Welsh, F.J. Dutko, and M.B.A. Oldstone. 1980. The virology and immunobiology of lymphocytic choriomeningitis virus infection. Adv. Immunol. 30:275-331.

28. Xiang, Z., and H.C. Ertl. 1995. Manipulation of the immune response to a plasmid-encoded viral antigen by co-inoculation with plasmids expressing cytokines. Immunity. 2:129-133.

29. Collins, P.L., R.M. Chanock, and K. McIntosh. 1996. Parainfluenza viruses. In Fields Virology. B.N. Fields, D.M. Knipe, and P.M. Howley, editors. Lippincott-Raven Publishers, Philadelphia. 1205-1241. 